\title{
Anaplastic lymphoma kinase protein expression predicts micrometastases and prognosis for patients with hepatocellular carcinoma
}

\author{
JIANHUA LIU ${ }^{1}$, HAOSHENG JIN ${ }^{2}$, HONGXIA TIAN ${ }^{3}$, GUODA LIAN $^{4}$, SHAOJIE CHEN $^{4}$, \\ JIAYU LI ${ }^{4}$, XUCHAO ZHANG ${ }^{3}$ and DONG MA ${ }^{1}$
}

\author{
${ }^{1}$ Department of Oncology, Cancer Center; ${ }^{2}$ Department of Hepatobiliary Surgery, Guangdong General Hospital; \\ ${ }^{3}$ Medical Research Center, Lung Cancer Institute, Guangdong General Hospital, Guangdong Academy of Medical Sciences, \\ Guangzhou, Guangdong 510180; ${ }^{4}$ Department of Gastroenterology, The Second Affiliated Hospital of Sun Yat-Sen University, \\ Guangzhou, Guangdong 510080, P.R. China
}

Received November 12,2014; Accepted September 24, 2015

DOI: $10.3892 / 01.2015 .3859$

\begin{abstract}
The present study aimed to investigate anaplastic lymphoma kinase $(A L K)$ status in hepatocellular carcinoma (HCC) and to evaluate whether abnormalities in expression were associated with patient prognosis. $A L K$ status was investigated using immunohistochemistry (IHC), reverse transcription-quantitative polymerase chain reaction (RT-qPCR) and fluorescence in situ hybridization (FISH) assays in 342 HCC patients. In addition, rapid amplification of complementary DNA ends-coupled PCR sequencing was performed, in order to confirm the presence of $A L K$ abnormalities in patients exhibiting $A L K$ messenger RNA (mRNA) overexpression. The correlation between $A L K$ expression and the clinicopathological features and prognosis of the HCC patients was statistically analyzed. The results of the present study revealed overexpression of ALK protein and mRNA; furthermore, $A L K$ gene copy number gains were observed via IHC (44.7\%; 153/342), RT-qPCR (47.4\%; $162 / 342)$ and FISH $(32.7 \%$; 112/342) analyses, although $A L K$ rearrangement or mutation was not demonstrated in the results of any of these assays. ALK protein expression levels were significantly associated with hepatitis $C$ virus $(\mathrm{HCV})$ status $(\mathrm{P}<0.001)$ and the presence of micrometastases $(\mathrm{P}=0.011)$. Within the entire patient cohort, $A L K$ expression was associated with poor progression-free survival (PFS; $\mathrm{P}=0.041$ ). Subsequent analysis in patient subgroups that demonstrated hepatitis B surface antigen positivity, HCV negativity, stage III-IV disease, recurrence and
\end{abstract}

Correspondence to: Dr Dong Ma, Department of Oncology, Cancer Center, Guangdong General Hospital, Guangdong Academy of Medical Sciences, 123 Huifu Road West, Guangzhou, Guangdong 510180, P.R. China

E-mail: madong8005@126.com

Key words: anaplastic lymphoma kinase, hepatocellular carcinoma, clinicopathological characteristics, micrometastases, prognosis micrometastasis positivity revealed that overall survival (OS) and PFS were significantly reduced in those patients exhibiting $A L K$ expression compared with those patients who were negative for $A L K$ expression. Multivariate analysis revealed that $A L K$ expression was an independent risk factor for OS $(\mathrm{P}=0.042)$ and $\mathrm{PFS}(\mathrm{P}=0.033)$, particularly for patients with stage III-IV tumors. Thus, ALK may serve as a novel indicator for the metastatic behavior and prognosis of HCC.

\section{Introduction}

Hepatocellular carcinoma (HCC) is the fifth most frequently diagnosed malignancy and the third most common cause of cancer-associated mortality globally (1). Previous evidence has suggested the existence of marked geographic variation, with a high prevalence of HCC in East Asian countries, particularly China (2). Although significant advances have been made with regard to surgical resection, ablation and chemotherapy (3), the prognosis of HCC remains unfavorable. As our understanding of the molecular mechanisms underlying the initiation and progression of HCC increases, targeted therapy has become a promising alternative to currently used treatments, representing a landmark in drug development and a significant step towards the development of personalized medicine for the treatment of HCC (4). However, the efficacy of existing targeted drugs has plateaued in recent years due to increasing drug resistance (5). Therefore, the discovery of novel molecular targets is urgently required for the development of more effective and efficient therapeutic agents.

In general, receptor tyrosine kinases (RTKs), which are crucial for signal transduction, are dysregulated in a diverse range of tumor types (6). The anaplastic lymphoma kinase $(A L K)$ gene, a proto-oncogene that encodes a transmembrane RTK, was initially identified in anaplastic large cell lymphomas carrying an abnormal $\mathrm{t}(2 ; 5)(\mathrm{p} 23 ; \mathrm{q} 35)$ translocation (7). Subsequently, its fusion variants were additionally identified in inflammatory myofibroblastic tumors (8) and diffuse large B-cell lymphomas (9). The human $A L K$ gene has a significant role in brain and neuronal development during 
embryogenesis, however, is downregulated in adults (10). It is well-known that genetic abnormalities involving $A L K$ include translocation (also known as 'rearrangement'), amplification and mutation, as well as $A L K$ overexpression $(11,12)$. DNA amplification and point mutations were originally identified in neuroblastoma, indicating that the $A L K$ gene may possess high carcinogenic and neoplastic potential (13). In addition, $A L K$ fusion oncogenes, resulting from chromosomal translocations, proved to be the most commonly observed $A L K$ aberrations in cancer, and were able to induce constant $A L K$ kinase activity via their own constitutive self-association, as well as acting as an oncogenic addiction pathway (14). A number of specific small-molecule $A L K$ inhibitors are capable of efficiently suppressing such activity (15).

Echinoderm microtubule-associated protein-like 4 (EML4)-ALK fusion variant was initially reported in 2007, as an oncological driver in non-small cell lung carcinoma (NSCLC) (16), and this led to a focus on the development of novel targeted agents for cancer diagnosis and therapy $(11,15)$. Subsequently, the success of crizotinib (PF-02341066), a targeted agent against EML4-ALK, in the treatment of advanced $A L K$-rearranged NSCLCs, led to an interest in the significance of $A L K$ status in various other epithelial malignancies, and represented the beginning of a novel era of the targeting of $A L K$ abnormalities for therapeutic purposes in solid tumors (17). Aberrant $A L K$ genes have been reported in various solid tumors (often in addition to hematological malignancies), including esophageal (18), breast (19), colorectal (20) and renal carcinoma (21), indicating an association between $A L K$ abnormalities and human cancer development. However, little research has been conducted to evaluate the abnormalities and clinical significance of the $A L K$ gene in $\mathrm{HCC}$.

In order to improve our current knowledge, the present study comprehensively detected $A L K$ gene status in a large $\mathrm{HCC}$ cohort, and investigated whether $A L K$ abnormalities are associated with patient clinicopathological features and prognosis.

\section{Materials and methods}

Clinical specimens and follow-up. A total of $342 \mathrm{HCC}$ tumor specimens and corresponding normal non-cancerous tissues were obtained from patients who had undergone surgical resection at Guangdong General Hospital (Guangzhou, China), between June 2005 and October 2010. For the performance of immunohistochemistry (IHC) and fluorescence in situ hybridization (FISH) assays, sections of the resected malignant tissues were fixed using $10 \%$ formalin and subsequently embedded in paraffin, followed by longitudinal slicing into $4-\mu \mathrm{m}$ thick serial sections. The remaining $\mathrm{HCC}$ tissues were frozen using liquid nitrogen and stored at $-80^{\circ} \mathrm{C}$, until required for intensive investigation by reverse transcription-quantitative polymerase chain reaction (RT-qPCR) and rapid amplification of complementary DNA (cDNA) ends (RACE)-coupled PCR sequencing. All patients had not received any anticancer therapy prior to surgery. Micrometastases were defined in accordance with the criteria proposed by $\mathrm{Hu}$ et al (22). Disease staging was based on the tumor-node-metastasis staging system of the Union for International Cancer Control (23). Clinical history was extracted from patient medical records. All patients received post-operative follow-up by telephone every 3 months for the initial 2 years of the study, and subsequently every 6 months until mortality or the study endpoint was reached. Overall survival (OS) and progression-free survival (PFS) were measured from the date of surgery until mortality/censoring or local recurrence/distant metastasis/censoring, respectively. The survival analysis utilized in the present study was designed to compare OS and PFS among patients. Each participant signed written informed consent for the use of their resected tissues and personal information for research purposes, and approval was obtained from the Ethics Committee of Guangdong General Hospital (Guangzhou, China).

ALK IHC analysis. ALK IHC staining was performed as previously described (24). In brief, unstained slides were successively submerged in xylene (Guangzhou Yikang Biological Science Technology Co., Ltd., Guangzhou, China), graded alcohol series and tap water for deparaffinization. Following deparaffinization, the intrinsic peroxidase activity of samples was inhibited using 3\% hydrogen peroxide. Antigen retrieval was performed by microwave heating at $95^{\circ} \mathrm{C}$, following submersion of the sections in ethylenediaminetetraacetic acid buffer ( $\mathrm{pH}$ 8.0; Shanghai Xibao Biological Technology Ltd., Shanghai, China). The samples were incubated with rabbit monoclonal anti-human ALK [D5F3 ${ }^{\circledR}$; Cell Signaling Technology, Inc., Danvers, MA, USA; 1:50 dilution in antibody diluent (Dako, Glostrup, Denmark)] at $4^{\circ} \mathrm{C}$ overnight; non-specific protein binding sites were blocked with $5 \%$ goat serum (Shanghai Xibao Biological Technology Ltd.). Subsequent to being washed, immunoreaction was visualized using biotinylated goat anti-rabbit IgG secondary polyclonal antibodies (dilution, 1:200; Santa Cruz Biotechnology, Inc., Santa Cruz, CA, USA) for $1 \mathrm{~h}$, and thereafter, streptavidin-horseradish-peroxidase complex (Shanghai Xibao Biological Technology, Ltd.) and 3-amino-9-ethyl carbazole (Shanghai Xibao Biological Technology, Ltd.) were added. Finally, all samples were counterstained using hematoxylin (Shanghai Xibao Biological Technology, Ltd.), dehydrated and sealed with cover slips for microscopic examination (CX31; Olympus Corporation, Tokyo, Japan). Two experienced investigators, who were blinded to the patient clinicopathological profiles, confirmed the immunostaining levels separately. The scoring scheme utilized to assess staining was as follows: 0 , absent staining; $1+$, weak cytoplasmic staining; $2+$, moderate and smooth cytoplasmic staining, and $3+$, strong and granular cytoplasmic staining in $\geq 10 \%$ of tumor cells (24).

ALK FISH analysis. FISH, a gold standard for confirming gene status, was applied to 342 unstained HCC samples with the Vysis $A L K$ Break Apart FISH Probe kit (Abbott Laboratories, Chicago, IL, USA) according to standard FISH protocols. Following deparaffinization, dehydration and treatment with citric acid, the tumor sections were washed with phosphate-buffered saline, followed by dehydration in alcohol and air-drying at $37^{\circ} \mathrm{C}$. Subsequently, the slides were added to $5 \mu \mathrm{l}$ of diluted $A L K$ probe and denatured. The probe was hybridized and the slides were washed. The reagent was comprised of two DNA probes labeled with Spectrum Orange 
A

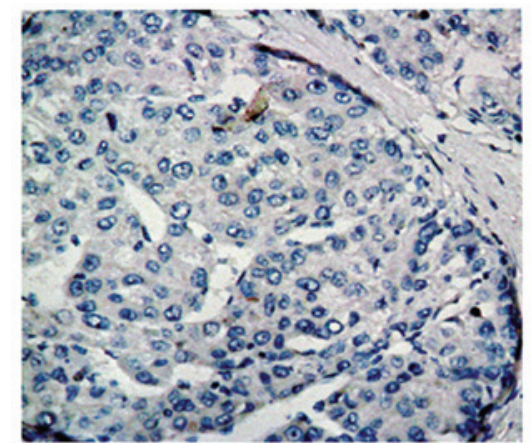

C

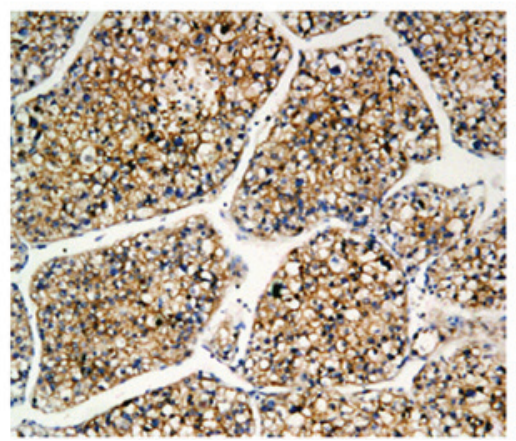

B

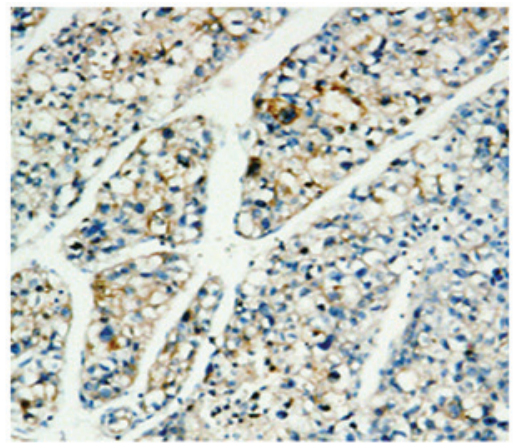

D

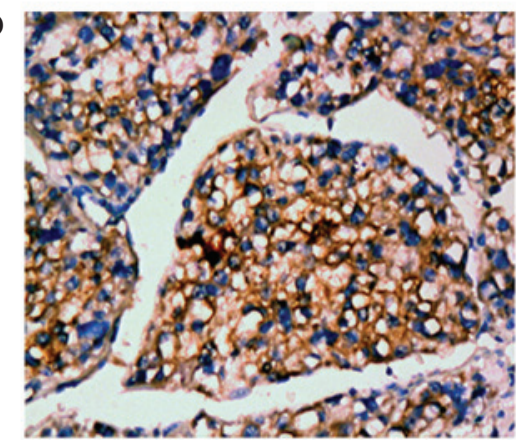

Figure 1. ALK protein expression visualized using immunohistochemistry in hepatocellular carcinoma samples. (A) Negative ALK staining in tumor cells (magnification, x200). (B) Faint (C) and strong cytoplasmic staining in tumor nests (magnification, x100). (D) Strong cytoplasmic staining in the majority of tumor cells (magnification, x200). ALK, anaplastic lymphoma kinase.

(red) and Spectrum Green (green), which were able to test various genetic rearrangements of $A L K$ at 2 p23, by hybridizing and breakpoint flanking. FISH signals were evaluated under a fluorescence microscope (IX72; Olympus Corporation) using an oil immersion objective. Two pathologists independently analyzed all FISH results. $A L K$ translocation positivity was defined as the separation of red and green signals, or a single red signal, in at least $15 \%$ of analyzed cells. However, since the criteria for gain of $A L K$ copy number have not been established, the present study adopted the previously published cut-off values for colorectal cancer in the current analysis (25). Briefly, the positivity for gain of $A L K$ gene copy number was considered to be $3-5$ copies of $A L K$ per cell in $\geq 10 \%$ of all detected cells, and amplification was regarded to be $\geq 6$ copies of $A L K$ per cell in $\geq 10 \%$ of all detected cells.

ALK RT-qPCR analysis. Total RNA was isolated from matching pairs of frozen HCC tissue blocks with TRIzol ${ }^{\circledR}$ reagent (Invitrogen; Thermo Fisher Scientific, Inc., Waltham, MA, USA) according to the manufacturer's protocols. Each tissue was trimmed at low temperature to protect the RNA from degradation. Prior to amplification, the purity and concentration of the extracted RNA were assessed using gel electrophoresis and absorbance at A260/A280. Reverse transcription for cDNA was subsequently conducted with a cDNA synthesis kit (Invitrogen; Thermo Fisher Scientific). cDNA was synthesized using $2.5 \mu \mathrm{g}$ of total RNA as template and $1 \mathrm{mmol} / \mathrm{l}$ oligo(dT) primer in $25 \mu \mathrm{l}$ of a solution that included 200 units of M-MLV reverse transcriptase. Subsequently, $5 \mu 1$ of cDNA was applied as the template in a $20-\mu 1$ reaction for RT-qPCR analysis with SYBR ${ }^{\circledR}$ GreenER $^{\text {TM }}$ qPCR SuperMix (Invitrogen; Thermo Fisher Scientific) and the ABI 7500 cycler (Applied Biosystems; Thermo Fisher Scientific) under the following thermal cycling conditions: $95^{\circ} \mathrm{C}$ for $2 \mathrm{~min}$, 40 cycles of $95^{\circ} \mathrm{C}$ for $15 \mathrm{sec}$ and a final extension at $72^{\circ} \mathrm{C}$ for $5 \mathrm{~min}$. The remaining generated cDNA was stored at $-20^{\circ} \mathrm{C}$ for further RACE-coupled PCR sequencing. $\beta$-actin served as the internal control. The primers were purchased from Shanghai GeneChem Co., Ltd. (Shanghai, China) and synthesized as follows: Sense, 5'-CCTGGAGCTGGTCATTACGA-3' and antisense, 5'-TGGTTTGTGAAGGAGCCATT-3'. The melting curve of each sample was analyzed in order to guarantee the product specification. As stated in a previous study (26), RT-qPCR analysis for $A L K$ was defined as positive when the specimen $\mathrm{Cq}$ value was $<30$.

RACE-coupled PCR sequencing analysis. Cases with RT-qPCR positivity were selected for RACE-coupled PCR sequencing analysis. Stored cDNA was purified using a High Pure PCR Product Purification kit (Roche Diagnostics, Indianapolis, IN, USA). Subsequently, reactions mixing purified cDNA were initiated by incubation at boiling temperature followed by incubation on ice. The following procedure was performed for targeted capture of rearranged sequences using previously published protocols (11). Following two successive runs of PCR, amplification of desired cDNA segments spanning exon 20 of the $A L K$ gene and upstream sequences, which may possess the transcript sequences of $A L K$ fusion partners, was achieved. The primers used were selected according to the study by Zhang et al (11), and were obtained from Shanghai GeneChem Co., Ltd. The first and second pairs of primers used were as follows: Sense, 5'-CGCGTCCACTAG TACGGGGGGGGGG-3' and antisense, 5'-GGCACCTCC TCGACGTCACTGATG-3'; and sense, 5'-GCGCACGGC TCCACTAGT-3' and antisense, 5'-ACCAGGAAACAGCTA TGACCGGTCTTGCCAGCAAAGCAGTAG-3', respectively. 
Following purification and labeling of the PCR products with M13 sequencing primer, 5'-GAAACAGCTATGACC-3', the amplified fragments were sequenced using the Genetic Analyzer 3730xl (Applied Biosystems; Thermo Fisher Scientific). The resulting files were aligned to the $A L K$ reference sequence (National Center for Biotechnology Information accession number, NM_004304.3) in order to determine whether $A L K$ mutations or fusions were present.

Statistical analysis. The $\chi^{2}$ test was performed in order to estimate the association between ALK protein expression and clinicopathological features. Kaplan-Meier survival curves were plotted with significance calculated using log-rank statistics. Independent prognostic markers of OS and PFS were assessed using univariate and multivariate proportional Cox models. $\mathrm{P}<0.05$ was considered to indicate a statistically significant difference. All data analysis was performed using SPSS version 18.0 (SPSS Inc., Chicago, IL, USA).

\section{Results}

ALK protein is detectable using IHC. ALK protein expression was investigated using IHC staining in all HCC biopsies (Fig. 1). In the normal non-cancerous (confirmed by histopathological examination) biopsied samples adjacent to the tumor samples, cytoplasmic $A L K$ staining was absent or poor, and occurred in very few cells (Fig. 1A). Of the 342 enrolled patients, 153 exhibited various degrees of brown cytoplasmic staining in the majority of tumor cells (Fig. 1B-D).

ALK status dectection via FISH. No HCC specimens demonstrated any evidence of rearrangement or amplification in the $A L K$ locus using a break-apart FISH assay. However, in 112/342 images, gain of $A L K$ gene copy number was observed, which was regarded as indicating FISH-positivity (Fig. 2A), and the remaining samples were regarded to be FISH-negative (Fig. 2B). Among the 112 FISH-positive patients, 108 were additionally positive for ALK protein expression identified via IHC.

ALK status detection via RT-qPCR and RACE-coupled PCR sequencing assays. In order to compare the levels of $A L K$ messenger RNA (mRNA) in 342 HCC specimens with that of adjacent non-cancerous tissues, RT-qPCR was performed. The results of the present study revealed that $A L K$ mRNA was significantly increased in 162 HCC samples. Notably, of the 162 cases exhibiting RT-qPCR positivity, 139 were IHC-positive and 101 were additionally FISH-positive (Table I). Fig. 3A illustrates nine representative cases. Furthermore, $A L K$ status was detected in 162 cases that were RT-qPCR positive using RACE-coupled PCR sequencing. Following alignment of the gene sequence with the $A L K$ reference sequence based on a previous study (11), no mutations or fusions with potential partners were detected (Fig. 3B).

Certain clinicopathological features are associated with ALK protein overexpression. The present study evaluated the association between $A L K$ gene expression and clinicopathological features of HCC patients (Table II). All analyses were performed according to IHC outcomes, as ALK protein was more stable than DNA and RNA, which assured comparability
Table I. Concordance among IHC, FISH and RT-qPCR results for anaplastic lymphoma kinase expression in 342 hepatocellular carcinoma patients.

\begin{tabular}{llcc}
\hline RT-qPCR & FISH & $\begin{array}{c}\text { IHC-positive } \\
(\mathrm{n}=153)\end{array}$ & $\begin{array}{c}\text { IHC-negative } \\
(\mathrm{n}=189)\end{array}$ \\
\hline Positive & Positive & 101 & 2 \\
Positive & Negative & 38 & 21 \\
Negative & Positive & 7 & 2 \\
Negative & Negative & 7 & 164 \\
\hline
\end{tabular}

IHC, immunohistochemistry; FISH, fluorescence in situ hybridization; RT-qPCR, reverse transcription-quantitative polymerase chain reaction.
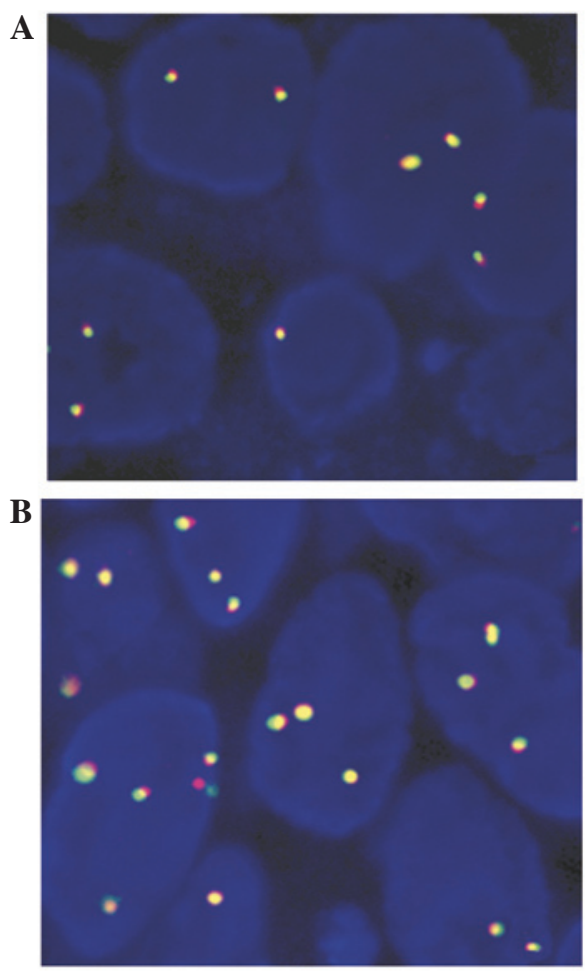

Figure 2. Fluorescence in situ hybridization results in representative tumor tissue samples from hepatocellular carcinoma patients. (A) Gain of ALK gene copy number positivity. (B) Gain of ALK gene copy number negativity. ALK, anaplastic lymphoma kinase. Magnification, x1,000.

among histological specimens. The results of the present study indicated that ALK protein expression was highly correlated with hepatitis $\mathrm{C}$ virus $(\mathrm{HCV})$ status $(\mathrm{P}<0.001)$ and micrometastases $(\mathrm{P}=0.011)$, however, it was not significantly associated with patient age, gender, hepatitis B surface antigen (HBsAg), $\alpha$-fetoprotein (AFP), cirrhosis, tumor size, tumor multiplicity, clinical stage, vascular invasion, Child-Pugh classification, recurrence and lymph node metastasis $(\mathrm{P}>0.05)$.

Survival analysis. By the cutoff day on June 1, 2013, 68.4\% (234/342) of the enrolled patients, all of whom exhibited recurrence or uncontrolled HCC, had succumbed. The median follow-up duration was 36.0 months (range, 0.6-79 months), 
Table II. Correlation between clinicopathological features and negative $(n=189)$ and positive $(n=153)$ anaplastic lymphoma kinase (ALK) protein expression in hepatocellular carcinoma patients.

\begin{tabular}{|c|c|c|c|c|}
\hline \multirow[b]{2}{*}{ Clinicopathological feature } & \multirow[b]{2}{*}{$\mathrm{n}$} & \multicolumn{2}{|c|}{ ALK protein } & \multirow[b]{2}{*}{ P-value } \\
\hline & & Negative, n (\%) & Positive, n (\%) & \\
\hline \multicolumn{5}{|l|}{ Age at diagnosis, years } \\
\hline$<60$ & 265 & $153(57.7)$ & $112(42.3)$ & 0.088 \\
\hline$\geq 60$ & 77 & $36(46.8)$ & $41(53.2)$ & \\
\hline \multicolumn{5}{|l|}{ Gender } \\
\hline Male & 270 & $145(53.7)$ & $126(46.7)$ & 0.165 \\
\hline Female & 72 & $45(62.5)$ & $27(37.5)$ & \\
\hline \multicolumn{5}{|l|}{ Hepatitis B surface antigen } \\
\hline Negative & 81 & $45(55.6)$ & $36(44.4)$ & 0.952 \\
\hline Positive & 261 & $144(55.2)$ & $117(44.8)$ & \\
\hline \multicolumn{5}{|l|}{ Hepatitis $\mathrm{C}$ virus } \\
\hline Negative & 324 & $189(58.3)$ & $135(41.7)$ & $<0.001$ \\
\hline Positive & 18 & $0(0.0)$ & $18(100.0)$ & \\
\hline \multicolumn{5}{|l|}{$\alpha$-fetoprotein, $\mathrm{ng} / \mathrm{ml}$} \\
\hline$<20$ & 169 & $90(53.3)$ & $79(46.7)$ & 0.460 \\
\hline$\geq 20$ & 173 & $99(57.2)$ & $74(42.8)$ & \\
\hline \multicolumn{5}{|l|}{ Cirrhosis } \\
\hline Absent & 155 & $90(58.1)$ & $65(41.9)$ & 0.343 \\
\hline Present & 187 & $99(52.9)$ & $88(47.1)$ & \\
\hline \multicolumn{5}{|l|}{ Tumor size, $\mathrm{cm}$} \\
\hline$<5$ & 189 & $108(57.1)$ & $81(42.9)$ & 0.437 \\
\hline$\geq 5$ & 153 & $81(52.9)$ & $72(47.1)$ & \\
\hline \multicolumn{5}{|l|}{ Tumor multiplicity } \\
\hline Single & 276 & $151(54.7)$ & $125(45.3)$ & 0.674 \\
\hline Multiple & 66 & $38(57.6)$ & $28(42.4)$ & \\
\hline \multicolumn{5}{|l|}{ Clinical stage } \\
\hline I-II & 163 & $90(55.2)$ & $73(44.8)$ & 0.986 \\
\hline III-IV & 179 & $99(55.3)$ & $80(44.7)$ & \\
\hline \multicolumn{5}{|l|}{ Vascular invasion } \\
\hline No & 210 & $117(55.7)$ & $93(44.3)$ & 0.832 \\
\hline Yes & 132 & $72(54.5)$ & $60(45.5)$ & \\
\hline \multicolumn{5}{|l|}{ Child-Pugh score } \\
\hline A & 316 & $177(56.0)$ & $139(44.0)$ & 0.331 \\
\hline $\mathrm{B}$ & 26 & $12(46.2)$ & $14(53.8)$ & \\
\hline \multicolumn{5}{|l|}{ Recurrence } \\
\hline No & 250 & $144(57.6)$ & $106(42.4)$ & 0.152 \\
\hline Yes & 92 & $45(48.9)$ & $47(51.1)$ & \\
\hline \multicolumn{5}{|l|}{ Lymph node metastasis } \\
\hline No & 288 & $153(53.1)$ & $135(46.9)$ & 0.066 \\
\hline Yes & 54 & $36(66.7)$ & $18(33.3)$ & \\
\hline \multicolumn{5}{|l|}{ Micrometastases } \\
\hline No & 297 & $172(57.9)$ & $125(42.1)$ & 0.011 \\
\hline Yes & 45 & $17(37.8)$ & $28(62.2)$ & \\
\hline
\end{tabular}

and $13(3.8 \%)$ cases were lost during the follow-up period. The potential effect of the $A L K$ gene on survival was assessed. In the total patient cohort, it was observed that OS did not significantly differ between patients with positive or negative ALK expression $\left(\chi^{2}=3.238\right.$; $\mathrm{P}=0.072$; Fig. 4A). However, PFS for patients with positive $A L K$ expression was significantly poorer 


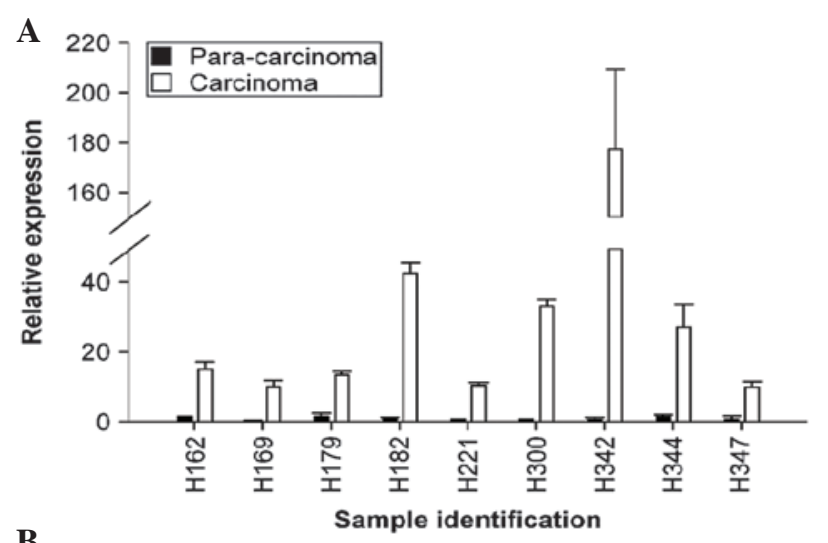

B

C CTGGTGCTTCCGGCGGT $\triangle C \triangle C \Delta \Delta T C \Delta T G$

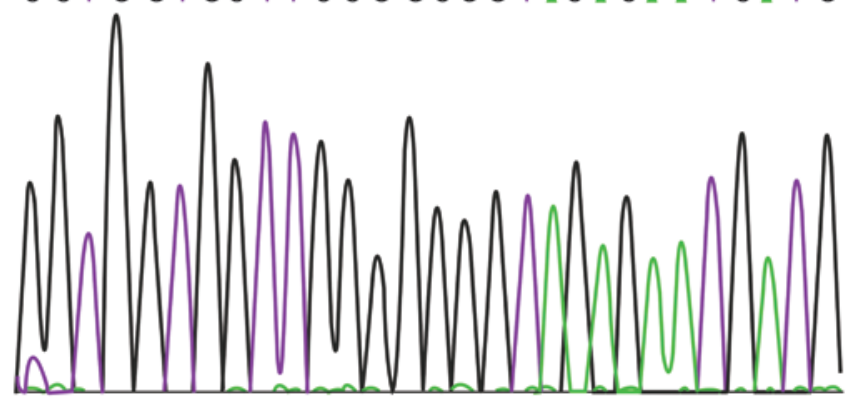

Figure 3. Detection of ALK status using reverse transcription-quantitative PCR and rapid amplification of complementary DNA ends-coupled PCR sequencing. (A) Results of transcriptional profiling revealing messenger RNA expression levels of the $A L K$ gene in 9 representative pairs of para-carcinoma and carcinoma tissues, from patients exhibiting hepatocellular carcinoma (B) Representative sequencing chromatograph demonstrating no presence of fusions or mutations in the $A L K$ gene. ALK, anaplastic lymphoma kinase; $\mathrm{PCR}$, polymerase chain reaction.

compared with that of patients with negative $A L K$ expression $\left(\chi^{2}=4.187 ; \mathrm{P}=0.041 ;\right.$ Fig. 4B). Following additional stratification of $342 \mathrm{HCC}$ patients, OS and PFS were found to be markedly reduced in patients exhibiting $A L K$ expression compared with patients without $A L K$ expression, in subgroups that were HBsAg positive ( $\mathrm{P}=0.026$ vs. 0.015 ; Fig. $5 \mathrm{~A}-\mathrm{B}$ ), $\mathrm{HCV}$ negative ( $\mathrm{P}=0.043$ vs. 0.021 ; Fig. $5 \mathrm{C}-\mathrm{D}$ ), stage III-IV ( $\mathrm{P}=0.002$ vs. 0.001 ; Fig. $5 \mathrm{E}-\mathrm{F})$, recurrence positive $(\mathrm{P}=0.029$ vs. 0.034 ; Fig. $6 \mathrm{~A}-\mathrm{B})$ and micrometastasis positive ( $\mathrm{P}=0.039$ vs. 0.036 ; Fig. $6 \mathrm{C}-\mathrm{D}$ ). However, in the HBsAg-negative $(\mathrm{P}=0.863$ vs. 0.869$)$, $\mathrm{HCV}$-positive (no comparison analysis), stage I-II ( $\mathrm{P}=0.895$ vs. 0.825$)$, recurrence-negative $(\mathrm{P}=0.375$ vs. 0.267$)$ and micrometastasis-negative ( $\mathrm{P}=0.184$ vs. 0.152$)$ subgroups, $A L K$ expression exerted no impact on OS or PFS. Furthermore, $A L K$ expression was not associated with survival stratified by age, gender, AFP, cirrhosis, tumor size, tumor multiplicity, vascular invasion, Child-Pugh classification and lymph node metastasis.

In addition, Cox proportional hazards model was applied in order to reveal the independent impacts of the following features on OS and PFS: Age, gender, HBsAg, HCV, AFP, cirrhosis, tumor size, tumor multiplicity, clinical stage, vascular invasion, recurrence, lymph node metastasis, micrometastases, Child-Pugh classification and ALK protein expression. The results of univariate and multivariate analyses indicated that ALK protein expression exerted a significant prognostic effect on PFS in HCC patients (hazard ratio, 1.365; 95\% confidence interval, 1.029-1.810; $\mathrm{P}=0.031$; Table III), although it was not
A

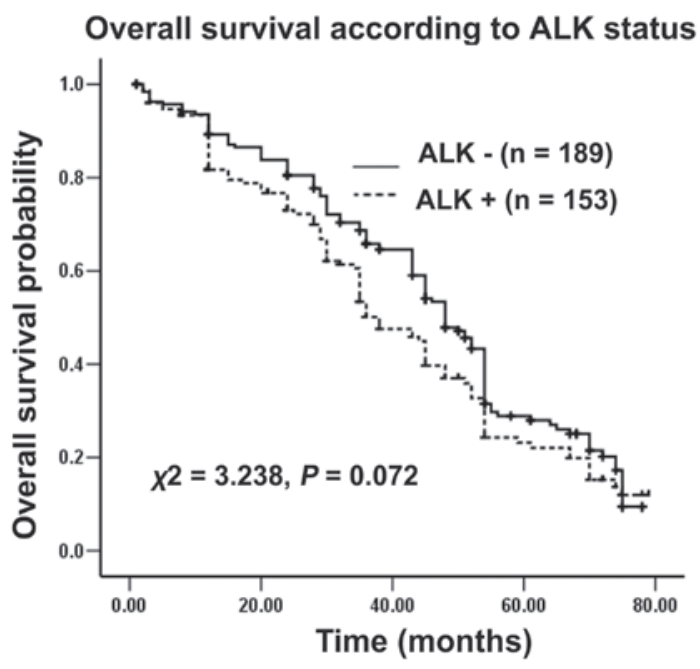

B

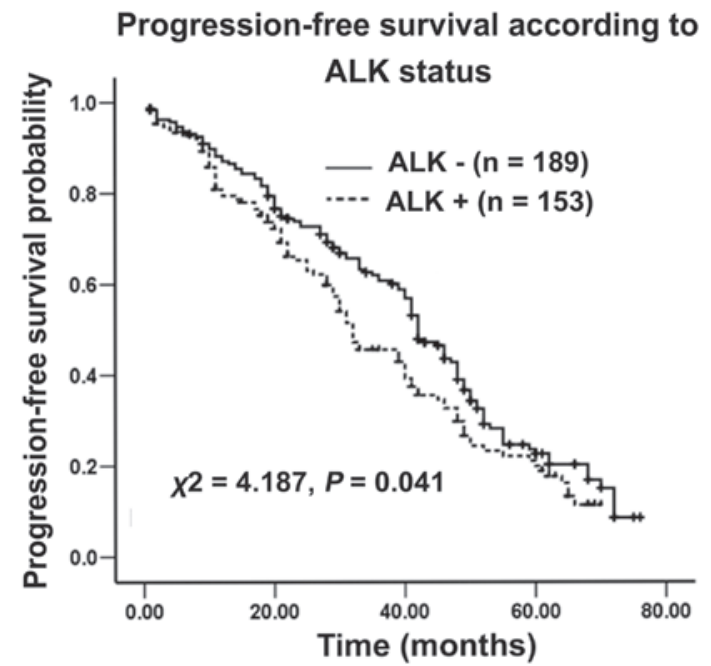

Figure 4. Kaplan-Meier survival curves of hepatocellular carcinoma patients. (A) Overall survival (ALK-negative vs. ALK-positive); (B) Progression-free survival (ALK-negative vs. ALK-positive). ALK, anaplastic lymphoma kinase.

an independent prognosticator for OS (hazard ratio, 1.290; 95\% confidence interval, 0.973-1.709; $\mathrm{P}=0.076)$. ALK protein expression may be an independent risk factor for OS ( $\mathrm{P}=0.041$ vs. 0.042$)$ and $\mathrm{PFS}(\mathrm{P}=0.029$ vs. 0.033 ; Table IV), particularly for stage III-IV patients.

\section{Discussion}

To the best of our knowledge, the results of the present study demonstrated the first evidence that $A L K$ expression was increased at a transcriptional level, and additionally at a translational level, in human HCC samples compared with adjacent normal tissue samples. $A L K$ rearrangement was not observed in any of the examined samples. The expression of ALK protein was significantly correlated with the aggressiveness and prognosis of primary HCC.

HCC is a pathologically and clinically heterogeneous neoplasm, exhibiting high malignancy and a consequent poor prognosis due to its aggressive features (27). Despite the complexity of hepatocarcinogenesis, the discovery of additional prognostic predictors and therapeutic targets for HCC has attracted particular interest. As a result, a number 
A HBsAg positive

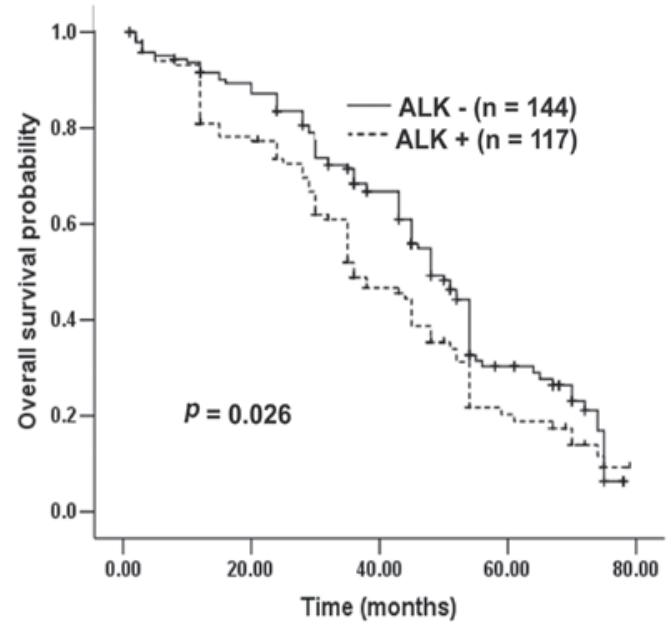

$\mathbf{C}$
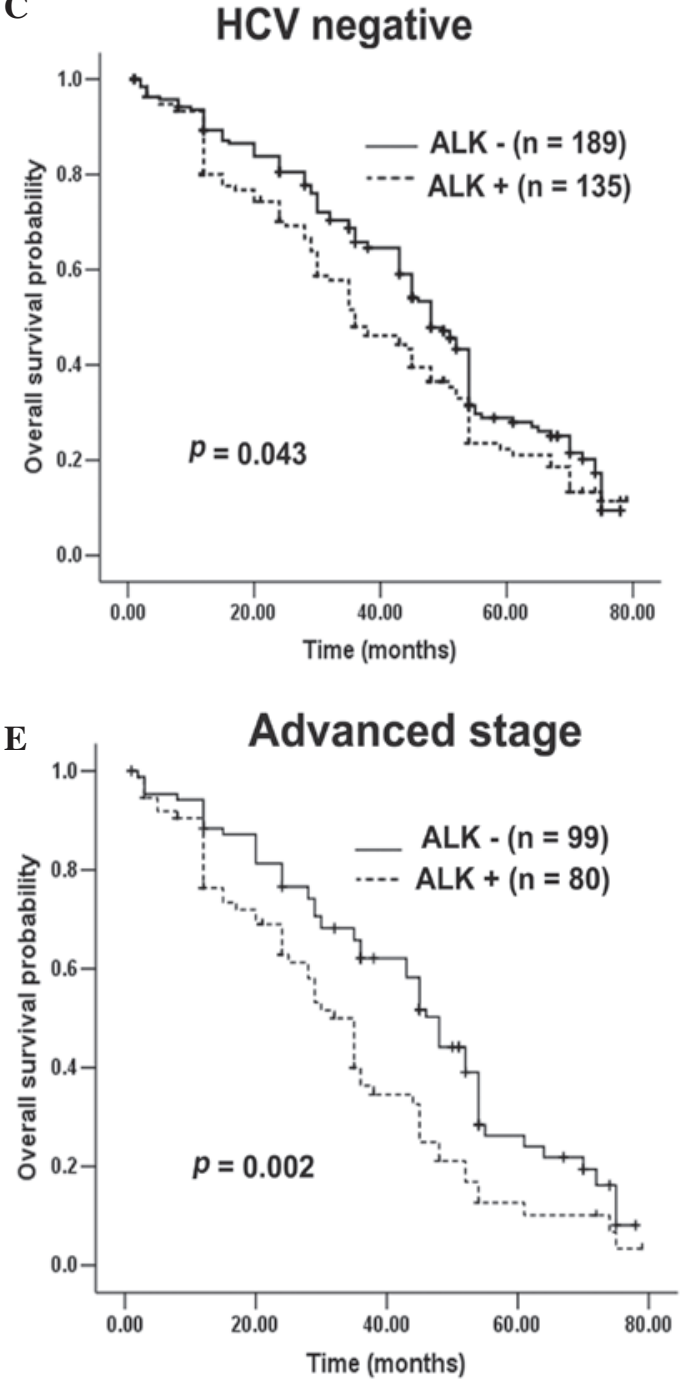

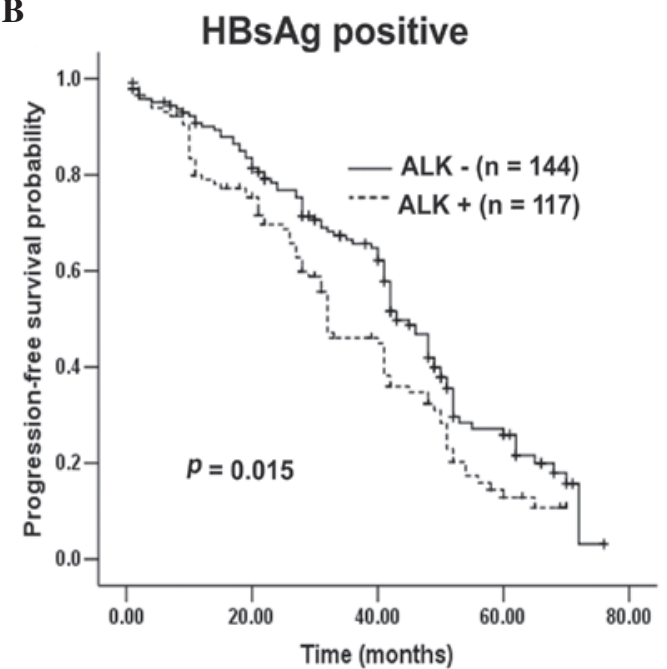

D

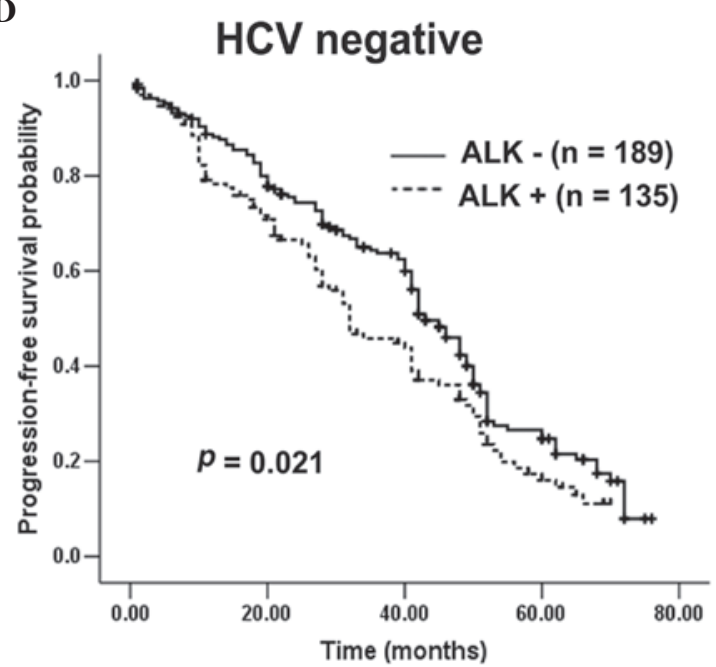

F

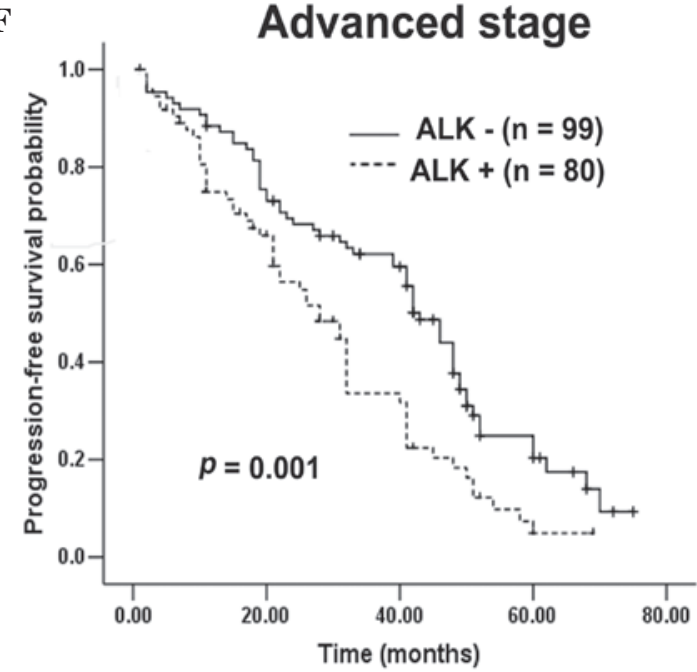

Figure 5. Kaplan-Meier survival curves of certain subgroups stratified according to clinicopathological features. (A) OS and (B) PFS (ALK-negative vs. ALK-positive) of patients exhibiting HBV infection. (C) OS and (D) PFS (ALK-negative vs. ALK-positive) of patients without HCV infection. (E) OS and (F) PFS (ALK-negative vs. ALK-positive) of patients exhibiting advanced stage (III-IV) tumors. OS, overall survival; PFS, progression-free survival; ALK, anaplastic lymphoma kinase; HBV, hepatitis B virus; HCV, hepatitis C virus; HBsAG, hepatits B surface antigen.

of genes, including epidermal growth factor receptor, transforming growth factor $\beta$ and $c-M E T$, have been identified as molecular targets of HCC (28). Recently, much attention has been paid to the $A L K$ gene, a member of the RTK family, the dysregulation of which is associated with abnormal development and malignant transformation in human cancer (29). 
A

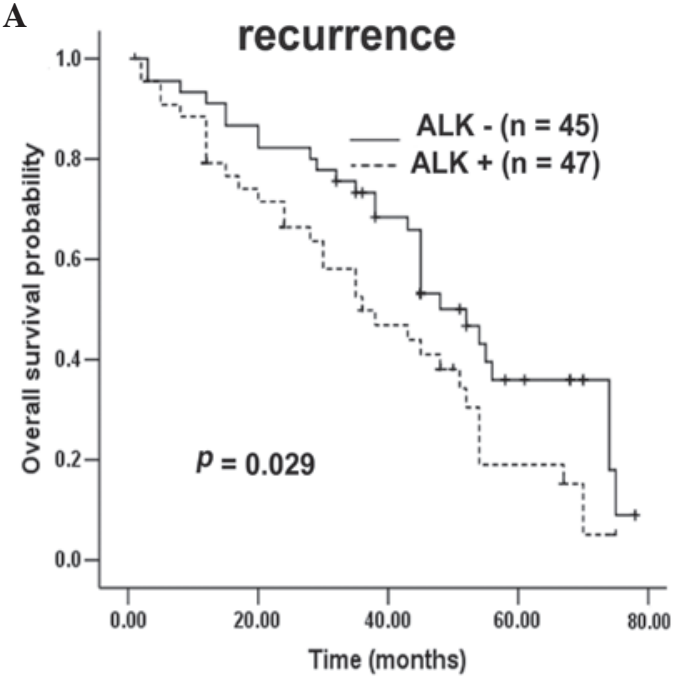

C

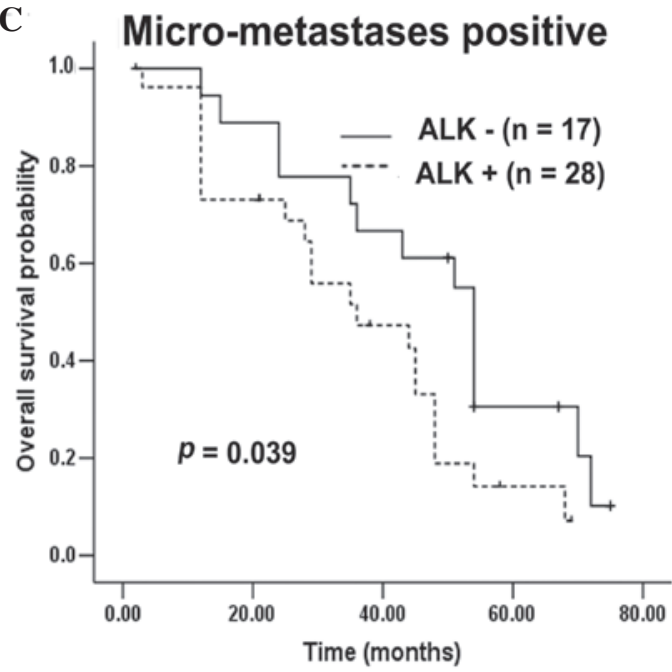

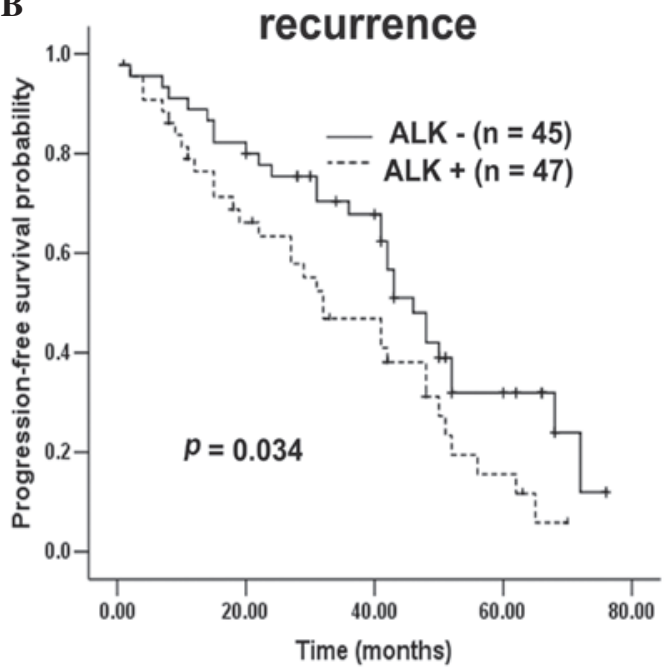

D

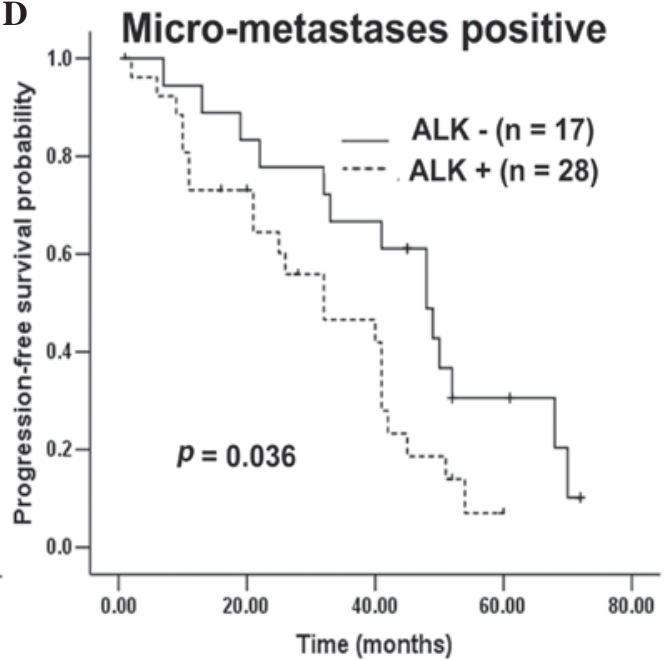

Figure 6. Kaplan-Meier survival curves of subgroups stratified according to certain clinicopathological features. (A) OS and (B) PFS (ALK-negative vs. ALK-positive) of patients with recurrence. (C) OS and (D) PFS (ALK-negative vs. ALK-positive) of patients exhibiting micrometastases. OS, overall survival; PFS, progression-free survival; ALK, anaplastic lymphoma kinase.

However, to the best of our knowledge, the clinical value of $A L K$ abnormalities in human HCC has not previously been comprehensively evaluated.

In the present study, $A L K$ status was investigated in a large cohort of HCC patients. IHC, RT-qPCR and FISH analyses revealed that increased expression of ALK protein and mRNA, as well as $A L K$ gene copy number gain, occurred in $\mathrm{HCC}$, with the rates of expression observed in patients being $44.7 \%$ (153/342), 47.4\% (162/342) and $32.7 \%$ (112/342), respectively. Notably, there was concordance in the assessment of $A L K$ expression levels among IHC, RT-qPCR and FISH detection methods, demonstrating that $A L K$ gene upregulation was present at post-transcriptional and transcriptional levels. Meanwhile, the results of the present study revealed that RT-qPCR possessed a higher sensitivity (90.8\%) and that FISH had increased specificity (97.9\%) compared with IHC staining, which demonstrated similar results to those of a previously published study (30). However, it is notable that $A L K$ overexpression or $A L K$ gene copy number gain is not indicative of $A L K$ rearrangement. To the best of our knowledge, in patients exhibiting NSCLC, copy number gain and amplification of the $A L K$ gene are reportedly highly expressed, while $A L K$ translocations are rare (13). Similar results have also been described in esophageal carcinoma (18). In the present study, no rearrangement, amplification or mutation of the $A L K$ locus was identified using FISH and RACE-coupled PCR sequencing assays. A recent retrospective study (12) reported that $A L K$ gene copy number gain was common in HCC investigated with FISH analysis, whereas $A L K$ rearrangement was not observed. These previous results supported the results of the present study, which indicated that the $A L K$ gene was upregulated in $\mathrm{HCC}$, and that this may be a potential biomarker for HCC.

The present study additionally characterized the association between ALK protein and the clinicopathological features of HCC. The results of the present study demonstrated that ALK protein overexpression possessed significant correlation with $\mathrm{HCV}$ status and micrometastases. Briefly, $A L K$ may be a valuable indicator for the identification of subsets of HCC cases with HCV infection and increased invasive tendency. Various experimental model systems have proved that $A L K$ gene overexpression contributes to cell migration 
Table III. Univariate and multivariate analyses of progression-free survival in 342 hepatocellular carcinoma patients.

A, Univariate analysis

\begin{tabular}{lllr}
\hline Parameter & \multicolumn{1}{c}{ Variable } & Hazard ratio $(95 \%$ confidence interval) & P-value \\
\hline Age at diagnosis, years & $<60$ vs. $\geq 60$ & $1.012(0.747-1.372)$ & 0.938 \\
Gender & Male vs. female & $0.880(0.635-1.219)$ & 0.443 \\
Hepatitis B surface antigen & Positive vs. negative & $1.068(0.787-1.449)$ & 0.673 \\
Hepatitis C virus & Positive vs. negative & $0.816(0.433-1.538)$ & 0.529 \\
$\alpha$-fetoprotein, ng/ml & $<20$ vs. $\geq 20$ & $0.932(0.721-1.205)$ & 0.591 \\
Cirrhosis & Absent vs. present & $1.026(0.791-1.330)$ & 0.849 \\
Tumor size, cm & $<5$ vs. $\geq 5$ & $1.143(0.883-1.478)$ & 0.310 \\
Tumor multiplicity & Single vs. multiple & $1.050(0.763-1.447)$ & 0.763 \\
Clinical stage & I-II vs. III-IV & $1.228(0.949-1.589)$ & 0.118 \\
Vascular invasion & No vs. yes & $1.113(0.854-1.450)$ & 0.430 \\
Recurrence & No vs. yes & $1.002(0.749-1.340)$ & 0.990 \\
Lymph node metastasis & No vs. yes & $1.099(0.779-1.550)$ & 0.591 \\
Micrometastases & No vs. yes & $1.397(0.974-2.004)$ & 0.069 \\
Anaplastic lymphoma kinase protein & Positive vs. negative & $1.304(1.005-1.691)$ & 0.045 \\
Child-Pugh classification & A vs. B & $6.220(3.764-10.278)$ & $<0.001$ \\
\hline
\end{tabular}

$\mathrm{B}$, Multivariate analysis

\begin{tabular}{lllr}
\hline Parameter & Variable & Hazard ratio (95\% confidence interval) & P-value \\
\hline Anaplastic lymphoma kinase protein & Positive vs. negative & $1.365(1.029-1.810)$ & 0.031 \\
Child-Pugh classification & A vs. B & $7.198(4.261-12.159)$ & $<0.001$ \\
\hline
\end{tabular}

Table IV. Univariate and multivariate analyses of overall survival for 179 stage III-IV hepatocellular carcinoma patients.

A, Univariate analysis

\begin{tabular}{llcr}
\hline Parameter & \multicolumn{1}{c}{ Variable } & Hazard ratio (95\% confidence interval) & P-value \\
\hline Age at diagnosis, years & $<60$ vs. $\geq 60$ & $1.026(0.700-1.505)$ & 0.894 \\
Gender & Male vs. female & $0.958(0.625-1.499)$ & 0.883 \\
Hepatitis B surface antigen & Positive vs. negative & $1.062(0.708-1.593)$ & 0.770 \\
Hepatitis C virus & Positive vs. negative & $0.885(0.389-2.014)$ & 0.771 \\
$\alpha$-fetoprotein, ng/ml & $<20$ vs. $\geq 20$ & $0.875(0.648-1.240)$ & 0.453 \\
Cirrhosis & Absent vs. present & $1.137(0.804-1.609)$ & 0.468 \\
Tumor size, cm & $<5$ vs. $\geq 5$ & $1.095(0.569-1.407)$ & 0.631 \\
Tumor multiplicity & Single vs. multiple & $1.264(0.725-2.203)$ & 0.408 \\
Vascular invasion & No vs. yes & $1.104(0.609-1.224)$ & 0.410 \\
Recurrence & No vs. yes & $1.091(0.744-1.599)$ & 0.656 \\
Lymph node metastasis & No vs. yes & $1.081(0.636-1.361)$ & 0.711 \\
Micrometastases & No vs. yes & $1.230(0.832-1.816)$ & 0.299 \\
Anaplastic lymphoma kinase protein & Positive vs. negative & $1.416(0.999-2.006)$ & 0.041 \\
Child-Pugh classification & A vs. B & $6.898(3.593-13.240)$ & $<0.001$ \\
\hline
\end{tabular}

B, Multivariate analysis

\begin{tabular}{llll}
\hline Parameter & \multicolumn{1}{c}{ Variable } & Hazard ratio (95\% confidence interval) & P-value \\
\hline Anaplastic lymphoma kinase protein & Positive vs. negative & $1.894(1.023-3.507)$ & 0.042 \\
Child-Pugh classification & A vs. B & $8.610(4.246-17.786)$ & $<0.001$ \\
\hline
\end{tabular}


and invasion $(10,31,32)$, which are crucial steps in the metastatic cascade, and may lead to distant organ involvement and tumor aggressiveness (33). Furthermore, Shao et al (34) reported that ALK protein was overexpressed in HCC and may be involved in the progression of HCC tumors, although the patient cohort investigated in this previous study was small. Similarly, the results of the present study suggested a significant impact of $A L K$ overexpression on the promotion of the development and metastasis of HCC.

Activation of proto-oncogenes and inactivation of tumor suppressors contributes to the occurrence and progression of malignancies. Specifically, the $A L K$ oncogene is activated by its endogenous ligands, midkine and pleiotrophin, which serve as mitogenic and angiogenic factors in cancer (10). Given that the activated $A L K$ gene induces an intricate system of downstream signaling cascades, including phosphoinositide 3-kinase/protein kinase B and mitogen-activated protein kinase pathways, it is possible that the $A L K$ gene may mediate cellular proliferation, motility and apoptosis, and thereby possess a significant role in the promotion of tumorigenesis and development in vitro and in vivo (35). Recently, Hasan et al (33) illustrated that MYC proteins that targeted key proliferative pathways in the cancer development process, and thus contributed to tumor growth and metastasis in neuroblastoma, regulated ALK expression. Notably, Di Paolo et al (36) reported that the RNA interference-based knockdown of $A L K$, independent of fusion gene status, resulted in the downregulation of proliferation and the upregulation of apoptosis in neuroblastoma tumor cells, thereby ultimately inhibiting tumor growth and prolonging survival in vivo. Therefore, these previous results confirm that $A L K$ has a significant role in the progression and metastasis of HCC.

In addition, $A L K$ overexpression has been documented as possessing an unfavorable prognosis in multiple human cancers, including neuroblastoma (36), breast carcinoma (37) and basal cell carcinoma (38). Similarly, the present study revealed that ALK protein was significantly correlated with poor PFS in the entire study cohort, particularly for patients with $\mathrm{HBsAg}$ positivity, HCV negativity, advanced stage tumors, recurrence or micrometastases. Notably, there were certain differences between the results of the present study and the previous findings of Jia et al (12), which demonstrated that $A L K$ gene copy number gain predicted the survival of patients exhibiting HBsAg negativity, however, did not impact on the survival of patients with HBsAg positivity. The primary reasons for the disagreement between these sets of results may be due to the genetic backgrounds and research methods utilized (protein versus gene copy number). The results of the current study concluded that the prognosis of HCC patients exhibiting $A L K$ overexpression tended to be poorer.

Due to the retrospective nature of the present study, a number of patients and their clinical information were lost to follow-up, particularly those patients who were not hospitalized following surgery, which may have led to bias in the results. Accordingly, additional experiments in vitro and in vivo are required to confirm the results of the present study. In addition, it remains to be elucidated whether HCC patients exhibiting $A L K$ overexpression may benefit from treatment with $A L K$ inhibitors. Further research focusing on these issues is required.

In conclusion, $A L K$ may serve as a valuable predictor of micrometastases and poor survival. Therefore, radiological diagnosis in combination with $A L K$ detection may assist with the prognostic evaluation of novel HCC cases, as optimal individualized therapeutic strategies remain to be devised.

\section{Acknowledgements}

The present study was supported by a grant from the Program of Science and Technology Commission Foundation of Guangzhou City, Guangdong Province, China (grant no. 2011B031800285).

\section{References}

1. Maluccio M and Covey A: Recent progress in understanding, diagnosing and treating hepatocellular carcinoma. CA Cancer J Clin 62: 394-399, 2012.

2. Schütte K, Bornschein J and Malfertheiner P: Hepatocellular carcinoma - epidemiological trends and risk factors. Dig Dis 27: 80-92, 2009.

3. Jemal A, Bray F, Center MM, Ferlay J, Ward E and Forman D: Global cancer statistics. CA Cancer J Clin 61: 69-90, 2011.

4. Song MJ and Bae SH: Newer treatments for advanced hepatocellular carcinoma. Korean J Intern Med 29: 149-155, 2014.

5. Tanaka S and Arii S: Molecular targeted therapies in hepatocellular carcinoma. Semin Oncol 39: 486-492, 2012.

6. Crose LE and Linardic CM: Receptor tyrosine kinases as therapeutic targets in rhabdomyosarcoma. Sarcoma 2011: 756982, 2011.

7. Morris SW, Kirstein MN, Valentine MB, Dittmer KG, Shapiro DN, Saltman DL and Look AT: Fusion of a kinase gene, ALK, to a nucleolar protein gene, NPM, in non-Hodgkin's lymphoma. Science 263: 1281-1284, 1994.

8. Gleason BC and Hornick JL: Inflammatory myofibroblastic tumours: Where are we now? J Clin Pathol 61: 428-437, 2008.

9. Laurent C, Do C, Gascoyne RD, Lamant L, Ysebaert L, Laurent G, Delsol G and Brousset P: Anaplastic lymphoma kinase-positive diffuse large B-cell lymphoma: A rare clinicopathologic entity with poor prognosis. J Clin Oncol 27: 4211-4216, 2009.

10. Webb TR, Slavish J, George RE, Look AT, Xue L, Jiang Q, Cui X, Rentrop WB and Morris SW: Anaplastic lymphoma kinase: Role in cancer pathogenesis and small-molecule inhibitor development for therapy. Expert Rev Anticancer Ther 9: 331-356, 2009.

11. Zhang X, Zhang S, Yang X, Yang J, Zhou Q, Yin L, An S, Lin J, Chen S, Xie Z, et al: Fusion of EML4 and ALK is associated with development of lung adenocarcinomas lacking EGFR and KRAS mutations and is correlated with ALK expression. Mol Cancer 9: 188, 2010

12. Jia SW, Fu S, Wang F, Shao Q, Huang HB and Shao JY: ALK gene copy number gain and its clinical significance in hepatocellular carcinoma. World J Gastroenterol 20: 183-192, 2014.

13. Salido M, Pijuan L, Martínez-Avilés L, Galván AB, Cañadas I, Rovira A, Zanui M, Martínez A, Longarón R, Sole F, et al: Increased ALK gene copy number and amplification are frequent in non-small cell lung cancer. J Thorac Oncol 6: 21-27, 2011.

14. Shaw AT and Solomon B: Targeting anaplastic lymphoma kinase in lung cancer. Clin Cancer Res 17: 2081-2086, 2011.

15. Shaw AT, Yeap BY, Mino-Kenudson M, Digumarthy SR, Costa DB, Heist RS, Solomon B, Stubbs H, Admane S, McDermott U, et al: Clinical features and outcome of patients with non-small-cell lung cancer who harbor EML4-ALK. J Clin Oncol 27: 4247-4253, 2009.

16. Soda M, Choi YL, Enomoto M, Takada S, Yamashita Y, Ishikawa S, Fujiwara S, Watanabe H, Kurashina K, Hatanaka H, et al: Identification of the transforming EML4-ALK fusion gene in non-small-cell lung cancer. Nature 448: 561-566, 2007.

17. Ou SH, Soo RA, Kubo A, Kawaguchi T and Ahn MJ: Will the requirement by the US FDA to simultaneously co-develop companion diagnostics (CDx) delay the approval of receptor tyrosine kinase inhibitors for RTK-rearranged (ROS1-, RET-, AXL-, PDGFR- $\alpha-$, NTRK1-) non-small cell lung cancer globally? Front Oncol 4: 58, 2014. 
18. Schoppmann SF, Streubel B and Birner P: Amplification but not translocation of anaplastic lymphoma kinase is a frequent event in oesophageal cancer. Eur J Cancer 49:1876-1881, 2013.

19. Lin E, Li L, Guan Y, Soriano R, Rivers CS, Mohan S, Pandita A, Tang J and Modrusan Z: Exon array profiling detects EML4-ALK fusion in breast, colorectal and non-small cell lung cancers. Mol Cancer Res 7: 1466-1476, 2009.

20. Lipson D, Capelletti M, Yelensky R, Otto G, Parker A, Jarosz M, Curran JA, Balasubramanian S, Bloom T, Brennan KW, et al: Identification of new ALK and RET gene fusions from colorectal and lung cancer biopsies. Nat Med 18: 382-384, 2012.

21. Debelenko LV, Raimondi SC, Daw N, Shivakumar BR, Huang D, Nelson $M$ and Bridge JA: Renal cell carcinoma with novel VCL-ALK fusion: New representative of ALK-associated tumor spectrum. Mod Pathol 24: 430-442, 2011

22. Hu ZY, Yuan SX, Yang Y, Zhou WP and Jiang H: Pleomorphic adenoma gene 1 mediates the role of karyopherin alpha 2 and has prognostic significance in hepatocellular carcinoma. J Exp Clin Cancer Res 33: 61, 2014.

23. Vauthey JN, Lauwers GY, Esnaola NF, Do KA, Belghiti J, Mirza N, Curley SA, Ellis LM, Regimbeau JM, Rashid A, et al: Simplified staging for hepatocellular carcinoma. J Clin Oncol 20 $1527-1536,2002$

24. Wang Z, Zhang X, Bai H, Zhao J, Zhuo M, An T, Duan J, Yang L, Wu M, Wang S, et al: EML4-ALK rearrangement and its clinica significance in Chinese patients with advanced non-small cell lung cancer. Oncology 83: 248-256, 2012.

25. Pietrantonio F, Maggi C, Di Bartolomeo M, Facciorusso MG, Perrone F, Testi A, Iacovelli R, Miceli R, Bossi I, Leone G, et al: Gain of ALK gene copy number may predict lack of benefit from anti-EGFR treatment in patients with advanced colorectal cancer and RAS-RAF-PI3KCA wild-type status. PLoS One 9: e92147, 2014

26. Zhang YG, Jin ML, Li L, Zhao HY, Zeng X, Jiang L, Wei P, Diao XL, Li X, Cao Q and Tian XX: Evaluation of ALK rearrangement in Chinese non-small cell lung cancer using FISH, immunohistochemistry and real-time quantitative RT-PCR on paraffin-embedded tissues. PLoS One 8: e64821, 2013.

27. Shiraha H, Yamamoto $\mathrm{K}$ and Namba M: Human hepatocyte carcinogenesis (review). Int J Oncol 42: 1133-1138, 2013.

28. Shen YC, Lin ZZ, Hsu CH, Hsu C, Shao YY and Cheng AL: Clinical trials in hepatocellular carcinoma: An update. Liver Cancer 2: 345-364, 2013.
29. Calero R, Morchon E, Johnsen JI and Serrano R: Sunitinib suppress neuroblastoma growth through degradation of MYCN and inhibition of angiogenesis. PLoS One 9: e95628, 2014

30. Wu YC, Chang IC, Wang CL, Chen TD, Chen YT, Liu HP, Chu Y, Chiu YT, Wu TH, Chou LH, et al: Comparison of IHC, FISH and RT-PCR methods for detection of ALK rearrangements in 312 non-small cell lung cancer patients in Taiwan. PLoS One 8: e70839, 2013.

31. George RE1, Sanda T, Hanna M, Fröhling S, Luther W 2nd, Zhang J, Ahn Y, Zhou W, London WB, McGrady P, et al: Activating mutations in ALK provide a therapeutic target in neuroblastoma. Nature 455: 975-978, 2008.

32. Duijkers FA, Gaal J, Meijerink JP, Admiraal P, Pieters R, de Krijger RR and van Noesel MM: High anaplastic lymphoma kinase immunohistochemical staining in neuroblastoma and ganglioneuroblastoma is an independent predictor of poor outcome. Am J Pathol 180: 1223-1231, 2012.

33. Hasan MK, Nafady A, Takatori A, Kishida S, Ohira M, Suenaga Y, Hossain S, Akter J, Ogura A, Nakamura Y, et al: ALK is a MYCN target gene and regulates cell migration and invasion in neuroblastoma. Sci Rep 3: 3450, 2013.

34. Shao CK, Su ZL, Feng ZY, Rao HL and Tang LY: Significance of ALK gene expression in neoplasms and normal tissues. Ai Zheng 21: 58-62, 2002 (In Chinese).

35. Kinoshita Y, Tajiri T, Ieiri S, Nagata K, Taguchi T, Suita S, Yamazaki K, Yoshino I, Maehara Y, Kohashi K, et al: A case of an inflammatory myofibroblastic tumor in the lung which expressed TPM3-ALK gene fusion. Pediatr Surg Int 23: 595-599, 2007

36. Di Paolo D, A mbrogio C, Pastorino F, Brignole C, Martinengo C, Carosio R, Loi M, Pagnan G, Emionite L, Cilli M, et al: Selective therapeutic targeting of the anaplastic lymphoma kinase with liposomal siRNA induces apoptosis and inhibits angiogenesis in neuroblastoma. Mol Ther 19: 2201-2212, 2011.

37. Krishnamurthy S, Woodward W, Yang W, Reuben JM, Tepperberg J, Ogura D, Niwa S, Huo L, Gong Y, El-Zein R, et al: Status of the anaplastic lymphoma kinase (ALK) gene in inflammatory breast carcinoma. Springerplus 2: 409, 2013.

38. Ning H, Mitsui H, Wang CQ, Suárez-Fariñas M, Gonzalez J, Shah KR, Chen J, Coats I, Felsen D, Carucci JA and Krueger JG: Identification of anaplastic lymphoma kinase as a potential therapeutic target in basal cell carcinoma. Oncotarget 4: 2237-2248, 2013. 